\title{
Odor-donor cue control of runway performance: A further examination
}

\author{
STEPHEN F. DAVIS \\ Austin Peay State University, Clarksville, Tennessee 37040 \\ ROBERT E. PRYTULA \\ Middle Tennessee State University, Murfreesboro, Tennessee 37130 \\ and \\ JAMES W. VOORHEES \\ Austin Peay State University, Clarksville, Tennessee 37040
}

\begin{abstract}
Two experiments are reported in which rats traversed a straight runway in the presence of odor cues from startbox-placed odor-donor rats. Experiment 1 investigated the importance of odor-donor and run-subject odor redundancy in determining appropriate start- and run-measure double-alternation patterning in the runway-trained animals. Patterning failed to develop when odor-donor and run-subject reinforcement schedules (i.e., odors) were inversely related (Phase 1), but was shown when the donor schedule was shifted to coincide with that of the run animals (Phase 2). The daily sequence of reward and nonreward events was randomized in Experiment 2. As patterning developed in all measures when donors were present and was selectively eliminated in the start and run measures when the donors were removed, it would appear that a fixed trial sequence is not a crucial factor in the production and utilization of these odor cues.
\end{abstract}

Dating from a publication by Ludvigson and Sytsma (1967), an accumulating body of research has established the finding that rat subjects in the enclosed runway can learn a double-alternation pattern of reward $(\mathrm{R})$ and nonreward $(\mathrm{N})$ based upon odors exuded by previous animals. Odors produced by animals actually traversing the runway appear to accumulate and have their maximum influence in the goal area (see Ludvigson \& Sytsma, 1967; Seago, Ludvigson, \& Remley, 1970). Thus, appropriate double-alternation patterning (i.e., fast to reward, slow to nonreward) appears to be limited to this segment of the apparatus when only runwaytrained subjects are tested. However, through direct placement of odor-donor subjects in selected segments of the runway, run-subject patterning has also been established in the start and run measures (Prytula \& Davis, 1974, 1976). As a reduction in N-trial speeds appears to be the most pronounced effect associated with the presence of odor donors (see Prytula \& Davis, $1974,1976)$, it would seem that the most salient odor exuded by them is that associated with frustrative nonreward.

The present experiments were designed to further assess the role of odor-donor cues in controlling runsubject performance in the start and run segments of the enclosed alleyway. In particular, we presented the

This research was supported by a Tower Fund research grant from Austin Peay State University to the first author, and a faculty research grant from Middle Tennessee State University to the second author. odor-donor subjects with a R-N schedule that was the inverse of the run-subject schedule (Experiment 1) and randomized the daily sequence of $\mathrm{R}$ and $\mathrm{N}$ events (Experiment 2).

\section{EXPERIMENT 1}

Experiment 1 was prompted by the apparent importance of the perfect coincidence of the odordonor and run schedules before odor-donor cues were utilized by the run subjects. The studies displaying this importance (Prytula \& Davis, 1974, 1976) used an initial phase, during which the two schedules perfectly coincided, and subsequent phases during which the odor-donor schedule was shifted in some fashion. Shifting the odor-donor schedule has consistently produced a lasting disruption in run-subject performance in the start and run segments of the alleyway. The purpose of Experiment 1 was to determine what effect an initial inverse relationship of odor-donor and runsubject schedules (i.e., odors) would have upon runsubject patterning. If perfect correspondence of schedules is a critical factor, then one would not expect patterning, based upon odor-donor cues exuded in the startbox, to develop in the start and run sections. However, goal-measure patterning, based upon odors exuded by previous run animals, would be expected. Shifting the odor-donor schedule to perfectly coincide with that of the run subjects should result in the development of patterning in the start and run measures. 


\section{Method}

Subjects. Twenty 90-day-old male albino rats purchased from the Holtzman Company, Madison, Wisconsin, served as subjects. All subjects were individually caged with water available on an ad-lib basis. One week prior to the start of pretraining, all subjects were placed on a food-deprivation regimen that maintained them at $85 \%$ free-feeding body weight. This deprivation schedule remained in effect for the duration of the experiment.

Apparatus. The apparatus consisted of a single straight runway $(11.4 \mathrm{~cm}$ wide $\mathrm{x} 12.7 \mathrm{~cm}$ high), having a gray startbox $(28.1 \mathrm{~cm})$, black run section $(91.4 \mathrm{~cm})$, and a black goalbox $(30.5 \mathrm{~cm})$. Masonite guillotine doors separated the startbox and goalbox from the run section. Start, run, and goal times, produced by the activation of a microswitch located on the start door and the interruption of a series of photoelectric cells (located 15.2, 92.4, and $116.8 \mathrm{~cm}$ beyond the start door, respectively), were recorded on all trials. A plastic receptacle recessed into the end wall of the goalbox served as the goal cup. A thin sheet of transparent plastic covered the top of the alley to prevent odors from dissipating.

Procedure. Two equal groups $(n=10)$, run and odor donor, were randomly formed at the beginning of pretraining. Each subject was assigned a permanent number $(1-10)$ within his respective group. A 4-day pretraining phase immediately preceded the experiment proper. Pretraining Days 1 and 2 consisted of handling and taming. On Pretraining Days 3 and 4, each run subject received a 5 -min exploration period in the unbaited apparatus with all photoelectric equipment operative. Subjects were habituated to the $45-\mathrm{mg}$ Noyes reward pellets in the home cage on all pretraining days.

Experimental testing was divided into two phases. During both phases of the experiment, all subjects received eight (four $R$ and four $N$ ) trials per day. Trials were administered to the run subjects in a RRNNRRNN sequence on all days. The daily Phase 1 sequence of the odor-donor subjects was NNRRNNRR; the daily Phase 2 sequence was RRNNRRNN. Thus, the two schedules were the inverse of each other during Phase 1 , but coincided perfectly during Phase 2. Phase 1 lasted 14 days (112 trials); Phase 2 was 3 days ( 24 trials) in length.

On all days all subjects received Trial 1 before Trial 2 was administered, and so on. To run a trial, the appropriate odor-donor subject (e.g., Odor Donor 1 always preceded Run Subject 1, etc.) was removed from the home cage and placed directly into the startbox. The odor donor was removed from the startbox as soon as reward (12 45-mg Noyes pellets) was consumed ( $R$ trials) or a 30 -sec confinement period had elapsed ( $\mathrm{N}$ trials). The appropriate run subject was immediately placed into the startbox. Following a 10-sec confinement, the run subject was allowed to traverse the runway. $\mathrm{R}$ and $\mathrm{N}$ events were identical for odor-donor and run subjects. The order for running odor-donor/run-subject pairs was randomized daily.

\section{Results and Discussion}

Figure 1 shows the mean start, run, and goal speeds (meters/second) for the run subjects during Phases 1 and 2. For purposes of graphical presentation and analysis, the speed scores for the eight-trial doublealternation sequence were combined in the following manner: The first two trials were averaged to yield a $R_{1}$ composite score, the next two trials were averaged to yield a $\mathrm{N}_{1}$ composite score, and so forth.

A Subjects by Treatments by Treatments analysis of variance performed on the data from the last 3 days of Phase 1 (the point at which patterning appeared to have been established in the goal measure) indicated that the

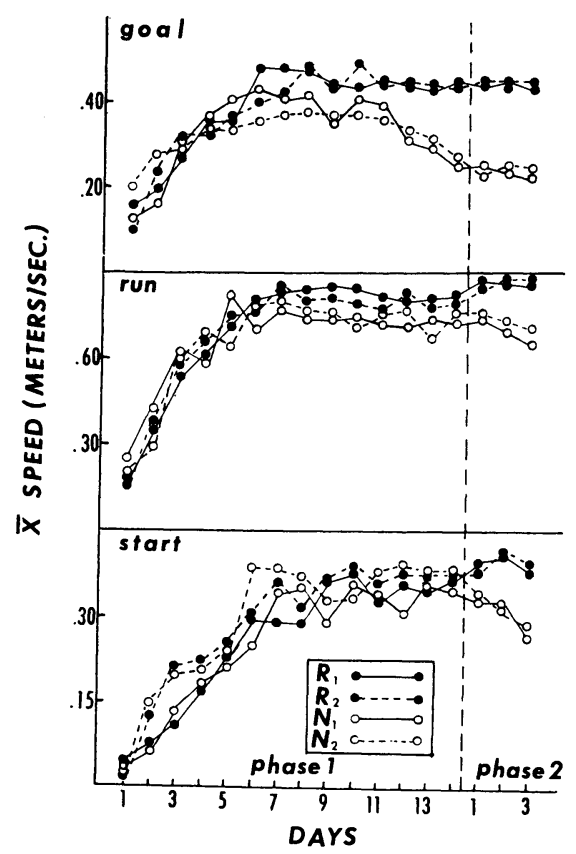

Figure 1. Mean start, run, and goal speeds, Experiment 1.

$\mathrm{R}$ vs. $\mathrm{N}$ factor was significant $[\mathrm{F}(1,45)=8.57, \mathrm{p}<.01]$ in the goal measure. Analysis of the Phase 2 data indicated that the $\mathrm{R}$ vs. $\mathrm{N}$ factor was significant in all three measures [start, $F(1,45)=5.53, p<.05$; run, $\mathrm{F}(1,45)=4.65, \mathrm{p}<.05$; goal, $\mathrm{F}(1,45)=8.92, \mathrm{p}<.01]$. Additionally, the R-N by Days interaction was found to be significant in the start $[F(2,45)=3.61, p<.05]$ and run $[F(2,45)=3.79, p<.05]$ measures. Further inspection of this interaction using Tukey's a procedure indicated that significant $(p<.05)$ R-N differences existed in the start and run measures on Days 2 and 3 of Phase 2.

The absence of patterning in the start and run measures during Phase 1 (inverse schedules) and the presence of such patterning during Phase 2 (corresponding schedules) lends additional support for the proposed importance of perfect correspondence of run and odor-donor schedules (i.e., odors). At present, the exact reason for the importance of this correspondence is not clear. The rapid acquisition of start- and runmeasure patterning in Phase 2 suggests that donor odors may have been present in the startbox during Phase 1 but were not attended to by the run subjects until the two R-N schedules corresponded perfectly. On the other hand, it may be that startbox-exuded odors were modified (possibly partially nullified) in some fashion during Phase 1 by odors of the opposite $\mathrm{R}$ or $\mathrm{N}$ event disseminating from the goalbox.

\section{EXPERIMENT 2}

In all of our previous studies using the odor-donor procedure, a constant double-alternation R-N schedule 
was employed. Experiment 2 was specifically designed to investigate the effectiveness of odor-donor cues in a situation involving random administration of daily trials. If the constant trial sequence has been instrumental in producing the observed behavior, then patterning might not be expected when such a sequence is lacking. However, if the donor cues are indeed as strong a determinant of behavior as the previous studies indicate, then patterning should also be displayed under the random-trial procedure. Furthermore, it would be expected that any patterning based upon odor-donor cues would be eliminated by removing the odor-donor animals from the apparatus.

\section{Method}

Subjects. Twenty male albino rats purchased from the Holtzman Company, Madison, Wisconsin, served as subjects. Deprivation and maintenance procedures were similar to those used in Experiment 1.

Apparatus. The apparatus used in Experiment 1 was used in Experiment 2.

Procedure. As in Experiment 1, two equal-sized groups $(n=10)$, run and odor donor, were randomly formed prior to pretraining. Each subject was assigned a permanent number (1-10) within his respective group. A 4-day pretraining phase similar to that employed in Experiment 1 immediately preceded experimental testing.

The order for daily trial administration was determined by a table of random numbers with the restrictions that each daily sequence must contain four $\mathrm{R}$ and four $\mathrm{N}$ events and that the same sequence could not occur on any 2 consecutive days. The same daily sequence was in effect for all subjects on any given day. During Phase 1 the donor subjects received their $\mathrm{R}$ and $\mathrm{N}$ events in the startbox. During Phase 2 all donor $\mathrm{R}$ and $\mathrm{N}$ events were administered in a neutral box in the same testing room as the runway. $\mathrm{R}$ and $\mathrm{N}$ events, confinement durations, randomization, and trial-administration procedures were identical to those used in Experiment 1. Experimental testing was divided into two phases. Phase 1 was 14 days (112 trials) in length; Phase 2 lasted 3 days ( 24 trials).

\section{Results and Discussion}

Prior to analysis, all latencies were reciprocated and multiplied by the appropriate constant to yield speed scores in meters/second. Daily $\mathrm{R}$ and $\mathrm{N}$ averages were then calculated for start, run, and goal measures for each subject. Mean start, run, and goal $\mathbf{R}$ and $\mathbf{N}$ speeds (meters/second) for the run subjects during Phases 1 and 2 are shown in Figure 2. An R-N by Days by Subjects analysis of variance performed on the data from the last 4 days of Phase 1 (the point at which appropriate responding had been developed in all measures) indicated that the $\mathrm{R}$ vs. $\mathrm{N}$ factor was significant in all three measures [start, $\mathrm{F}(1,63)=8.13, \mathrm{p}<.01$; run, $\mathrm{F}(1,63)=5.32, \mathrm{p}<.05 ;$ goal, $\mathrm{F}(1,63)=4.86, \mathrm{p}<.05]$. Additionally, the days factor was significant in the start $[F(3,63)=3.59, p<.05]$ and run $[F(3,63)=3.21$, $\mathrm{p}<.05]$ measures. The R-N by Days interaction was significant in all three measures [start, $F(3,63)=3.76$, $\mathrm{p}<.05$; run, $\mathrm{F}(3,63)=3.12, \mathrm{p}<.05$; goal, $\mathrm{F}(3,63)=$ $3.76, p<.05]$. Subsequent analysis of this interaction using Tukey's a procedure indicated that significant

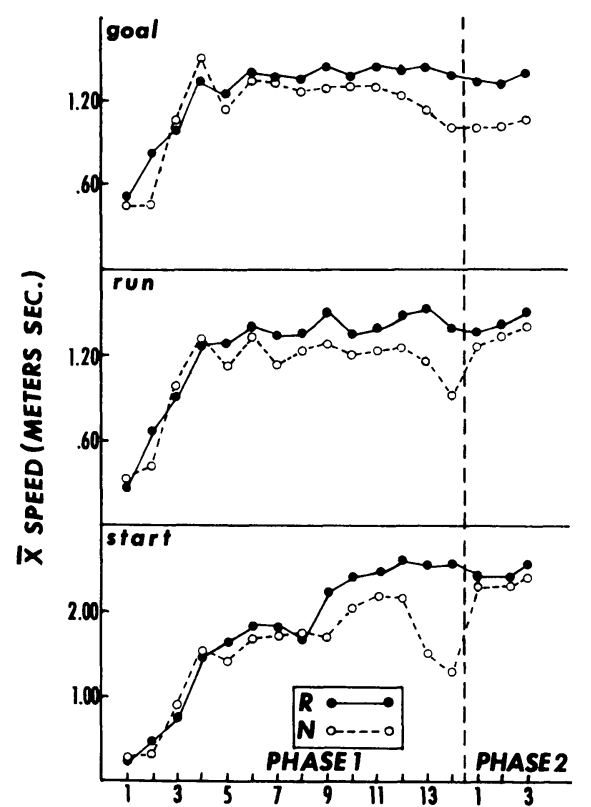

Figure 2. Mean start, run, and goal speeds, Experiment 2.

$\mathrm{R}$ vs. $\mathrm{N}$ differences $(\mathrm{p}<.05)$ existed at Days $12-14$ in all three measures. A similar analysis of variance performed on the data from Phase 2 yielded a significant $[F(1,45)=7.67, p<.01] R$ vs. $N$ effect in the goal measure.

The appropriate responding shown in the start and run measures during Phase 1 (donors present) and the lack of such patterning in these measures during Phase 2 (donors absent) indicates that donor odors were effectively controlling performance in these segments of the apparatus under the random-trial procedure. The finding that patterned responding in the goal measure was not disrupted by removal of the donor subjects (Phase 2) suggests that performance in this segment was under the control of odors exuded there by previous run animals.

Despite the occurrence of significant $\mathrm{R}$ vs. $\mathrm{N}$ differences, the averaging of daily $R$ and $N$ events effectively obscured any indication of appropriate trial-by-trial responding within each day. Figure 3 shows trial-by-trial means for the last 2 days of Phase 1 and Day 1 of Phase 2. Here it can be seen that appropriate changes were shown in all measures on Days 13 and 14 of Phase 1. However, the removal of donors (Phase 2) resulted in an immediate disruption of patterning in the start and run measures. Slightly elevated speeds on Trials 1 and 6 in the run measure and Trial 6 in the start measure of Day 1 (Phase 2) suggest the possibility that the run subjects may have become sensitized to odors disseminating from the goalbox.

\section{GENERAL DISCUSSION}

The establishment of patterning under the random-trial procedure (see Figures 2 and 3, Experiment 2) indicates that 


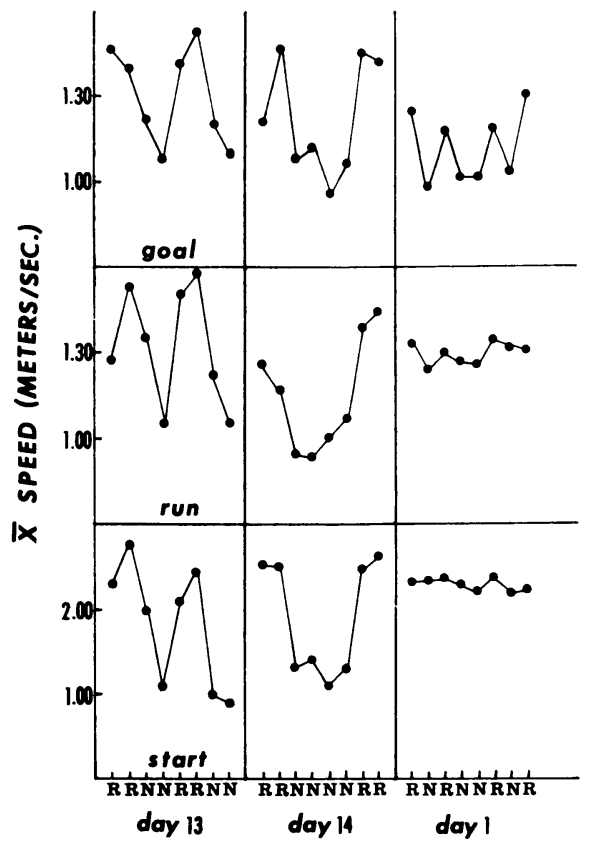

Figure 3. Mean start, run, and goal speeds by trials on Days 13 and 14 (Phase 1) and Day 1 (Phase 2), Experiment 2.

the effectiveness of odor cues is not limited to only those situations in which a constant sequence of trial administration (e.g., RRNNRRNN) is used. Figures 2 and 3 also indicate that the removal of the odor donors (unlike shifting the odor-donor R-N schedule) did not have any effect on goal measure patterning.

The establishment of goal-measure patterning, and the lack of such patterning in the start and run measures, when the odor-donor and run schedules (i.e., odors) were initially inverse (see Figure 1; Experiment 1, Phase 1) lends additional support for the proposed importance of the redundancy and predictiveness of the odor-donor cues. It should be noted that these data do not rule out the possibility of establishing patterning when donor-run reinforcement schedules are inversely related. For example, Eslinger and Ludvigson (Note 1) have recently reported that such patterning can be established when two goalboxplaced donor animals are used prior to each run animal and the apparatus is swabbed between run animals. In view of this, the present data suggest that odor-cue redundancy is more important in those situations (1) employing startbox-placed donors, and/or (2) allowing the accumulation of odors.

\section{REFERENCE NOTE}

1. Eslinger, P. J., \& Ludvigson, H. W. Do constraints exist on discriminative use of odors resulting from reward and nonreward in the rat? Paper presented at the Annual Meeting of the Psychonomic Society, San Antonio, November 1978.

\section{REFERENCES}

Ludvigson, H. W., \& Sytsma, D. The sweet smell of success: Apparent double alternation in the rat. Psychonomic Science, 1967, 9, 283-284.

Prytula, R. E., \& Davis, S. F. Runway performance as a function of positively and negatively correlated olfactory cues. Psychological Reports, 1974, 35, 735-740.

Prytula, R. E., \& Davis, S. F. The relationship between locus of odor cues and double-alternation responding in the rat. Animal Learning \& Behavior, 1976, 4, 352-356.

Seago, J. D., Ludvigson, H. W., \& Remley, N. R. Effects of anosmia on apparent double-alternation in the rat. Journal of Comparative and Physiological Psychology, 1970, 71, 435-442.

(Received for publication January 15, 1979.) 